\title{
Laser Heat Treatment of Low-Alloy Ultrahigh-Strength Steel Laser-Welded Joints
}

\author{
Laser heat treatment was performed to improve the bending property of laser- \\ welded joints of low-alloy ultrahigh-strength steel with minimized strength loss
}

\author{
BY C. LUO, Y. CAO, L. ZHAO, AND J. SHAN
}

\begin{abstract}
The poor bending property of laser-welded joints limits the application of low-alloy ultrahigh-strength steel (LAUHSS). In this work, two stages of laser heat treatment (LHT) were performed to enhance the face- and back-bending property of joints with minimized strength loss. The microstructures and mechanical properties were evaluated, and the influence mechanism of LHT on the bending property was discussed. The first LHT aimed to improve the back-bending property, after which the joints were comprised of the austenized and tempering zones. In the tempering zone, the original inhomogeneous microstructures transformed into similar tempered martensite. This smoothed out the steep hardness gradient to relatively uniform values. In the austenized zone, austenization occurred and the hardness valley still existed around the sides of the zone. The mechanical property test results showed the back-bending angle could be improved from 30 deg to more than $90 \mathrm{deg}$, while the face-bending angle showed unsatisfactory results with more than $1280 \mathrm{MPa}$ tensile strength. The second LHT was performed based on the first LHT to improve the face-bending property of joints. With lower power in the second LHT, the dual-phase microstructures in the austenized zone tempered. Additionally, the hardness distributions of joints tended to be more uniform without valleys. A more than 90-deg face-bending angle and about $1205 \mathrm{MPa}$ tensile strength were obtained. After LHT, the range of plastic deformation during the bending process expanded instead of concentrating in the hardness valley zone, which led to a larger relative bending radius and less tensile stress on the bending surface. This is beneficial for the improvement of the bending property.
\end{abstract}

\section{KEYWORDS}

- Low-Alloy Ultrahigh-Strength Steel $\bullet$ Bending Property

- Laser-Welded Joints • Relative Bending Radius

- Laser Heat Treatment • Tensile Strength

\section{Introduction}

Fuel efficiency, safety, and environmental impact are key issues for the automotive industry, which is the driving force for the use of low-alloy ultrahigh-strength steel (LAUHSS) because of its beneficial combination of high strength/weight ratio and good toughness (Refs. 1, 2). In general, LAUHSS is used in the quenched and tempered conditions (Refs. 1, 3). Tempering at low temperature is carried out to obtain a high tensile strength up to $1700 \mathrm{MPa}$, as well as high hardness with the microstructures of martensite.

The most essential welding technique of LAUHSS is arc welding with filler metal (Refs. 4, 5). However, related research has revealed that tensile strength of arc-welded joints is generally less than $1000 \mathrm{MPa}$, and the joint efficiency (tensile strength ratio of joints to base metal) is usually lower than 60\% (Refs. 6-8) because the microstructures of weld metal (WM) mainly consist of the soft phase, such as austenite and $\delta$-ferrite (Refs. 8, 9).

Laser welding has become an efficient technique to improve joint strength, which gives a relatively narrow weld and restricted heat-affected zone (HAZ) due to its characteristics of high power density and low heat inputs (Refs. 10, 11). More importantly, the fine martensite structure can be obtained in the weld, which contributes to the similar tensile strength of joints in comparison with the base metal (Ref. 12). Some studies on laser welding of LAUHSS with more than $1500 \mathrm{MPa}$ tensile strength show that up to $90 \%$ joint efficiency could be obtained (Refs. 12-14).

However, one of the most primary challenges in the laser welding of LAUHSS is the poor formability of joints, especially in the bending property. It was reported (Ref. 15) that fiberlaser-welded joints of $0.3 \mathrm{C}-1 \mathrm{Cr}-1 \mathrm{Si}$ steel could just bend to less than a 40-deg angle before failing. For the bending test of laser-welded Armox 500T steel (Ref. 5), all the joints could merely reach $45-50 \mathrm{deg}$. Most of the laser-welded joints of LAUHSS broke in the HAZ with small bending angles (Refs. 5 , 15). However, a bending angle of 90 deg after springback is needed in practical applications (Ref. 16). Related studies show that the inhomogeneous mechanical properties of samples strongly affect the formability of the joints (Refs. 17, 18). The presence of a reduced-hardness layer in the HAZ would result in strain localization in the softening region and small bending angles (Refs. 19, 20). Similar results were also reported by Mohammadi et al. (Ref. 21).

The HAZ softening during welding of LAUHSS is usually 


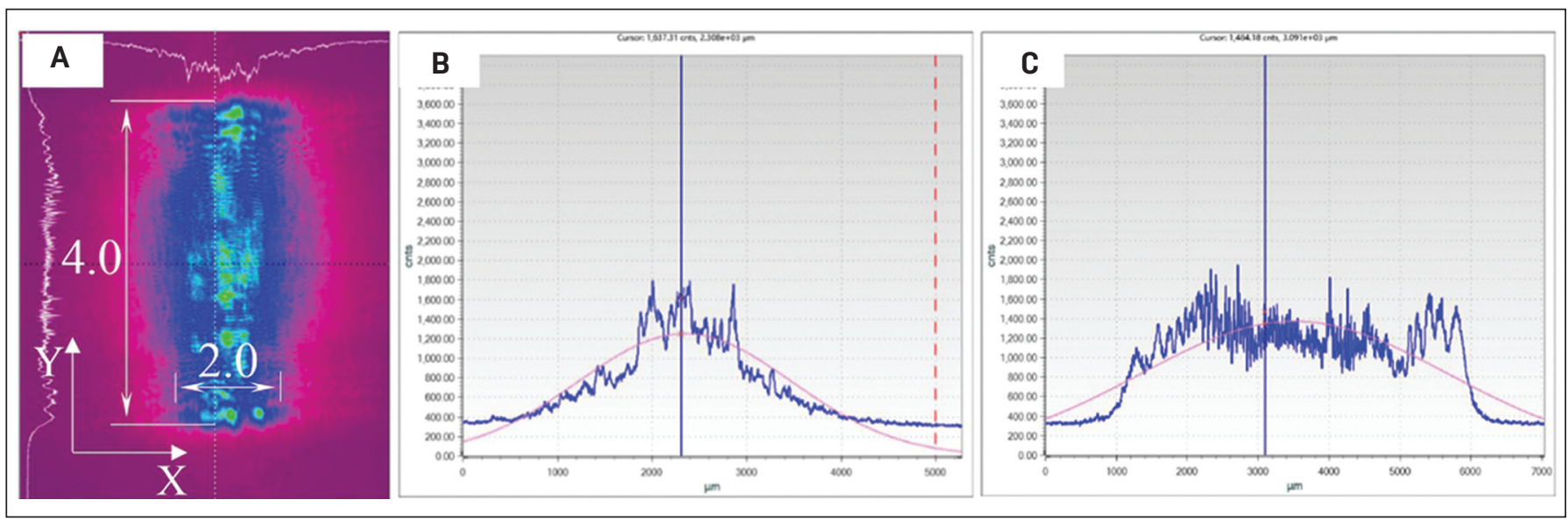

Fig. 1 - Light distribution of the rectangular spot: $A$ - Overall energy distribution; $B$ - energy distribution along the $x$-axis; $C-$ energy distribution along the $y$-axis.

inevitable (Ref. 22). Studies on the softening behavior of the HAZ demonstrate that the phenomenon is caused by tempering of preexisting martensite in the subcritical HAZ (Ref. 23). Low-alloy ultrahigh-strength steel usually contains few strengthening elements and, therefore, has no characteristics of age hardening. The tensile strength and hardness decrease gradually with the increase of tempering temperature (Ref. 24), which results from the carbide precipitation from martensite, coarsening of lath, and decrease of dislocation density (Ref. 24).

One effective way to eliminate the joint's inhomogeneity is postweld heat treatment (Refs. 15, 25). As LAUHSS is always used with large-sized joints, it is more appropriate to treat the joints locally instead of whole heat treatment. Since tempering would degrade the strength and hardness of the LAUHSS, a local heat treatment process with a smaller affected zone is needed to minimize strength loss.

Laser is extremely advantageous in precise local heating because of its superior properties, such as rapid heating, great flexibility, and remote fabrication (Refs. 10, 26, 27). It gains advantages from the thermal gradient caused by a moving heat source (Ref. 28). Laser radiation is absorbed on the surface of sheets, resulting in sharp temperature gradients through the affected zone, while the rest of the sheets stay unaffected (Refs. 29, 30). Moreover, the combination of laser welding and laser local heating would greatly improve the processing efficiency because the equipment and fixtures used are similar.

The heat treatment temperature of LHT can be adjusted by parameters such as laser power, spot size, and scanning speed (Refs. 21, 29, 31). As expected, the temperature usually rises when increasing the power and decreasing speed (Refs. 21, 29). A smaller spot size could result in higher power density at the laser irradiation position, which would affect the distribution of temperature. Furthermore, since the absorption rate of the laser inevitably has an effect on the temperature, the type of lasers is also a crucial factor. Based on the relevant research (Refs. 21, 29, 32), it can be found that diode lasers and solid-state lasers, such as the $\mathrm{Nd}$ :YAG laser, are more commonly used compared to gas lasers.

Suitability of LHT to improve the formability of homoge- neous samples has been confirmed in previous studies (Refs. $28,33,34)$. Large amounts of research have been made on the effect of LHT on plasticity. The results reveal significant increases in elongation (Refs. 30, 31, 35) and reduction of area (Ref. 36). Few works have been done to improve the bending property by LHT. In a study on H320LA steel (Ref. 36), the problem of cracking during the bending test was addressed by LHT. Subsequently, the steel could bend to 90 deg without cracking. Local laser heat treatments of WR500 martensitic steel were reported (Ref. 31). It was seen that the ratio between the minimum bending radius and the sheet thickness ( $r / t)$ greatly decreased, which means the bendability was significantly enhanced. Similar results were also observed by Bammer et al. (Ref. 37). All the studies indicate LHT is significantly effective in improving the bending property of samples, but most of the research has concentrated on homogeneous samples instead of welded joints. To date, limited works have been published regarding improvement of the bending property of joints, and the feasibility has not been confirmed.

The purpose of this work was to study the effect of LHT on the bending property of laser-welded joints of LAUHSS. The microstructures, microhardness, bending property, and tensile strength of joints were assessed. Additionally, the influence mechanism of LHT on the bending property of joints was discussed.

\section{Material and Methods}

Three 3-mm-thick, 1700-MPa LAUHSS plates with the dimensions of $60 \times 100 \mathrm{~mm}$ were used in this study. The chemical compositions are listed in Table 1 . The as-supplied state of the steel was solution-annealed in an inert environment at $800^{\circ} \mathrm{C}$ for $1 \mathrm{~h}$, then oil cooled to room temperature, and finally tempered at $200^{\circ} \mathrm{C}$ for $1 \mathrm{~h}$.

Laser welding was realized with an IPG YLS-2000 fiber laser. As a focused spot is beneficial for exploiting the advantages of laser welding, $0 \mathrm{~mm}$ was used in the welding progress. Based on the optimized experiments, the parameters of laser power, welding speed, and defocusing amount were $2.0 \mathrm{~kW}, 1.5 \mathrm{~m} / \mathrm{min}$, and $0 \mathrm{~mm}$, respectively. High-purity argon was supplied as the shielding gas with a flow rate of $15 \mathrm{~L} / \mathrm{min}$ at the front and back sides. 


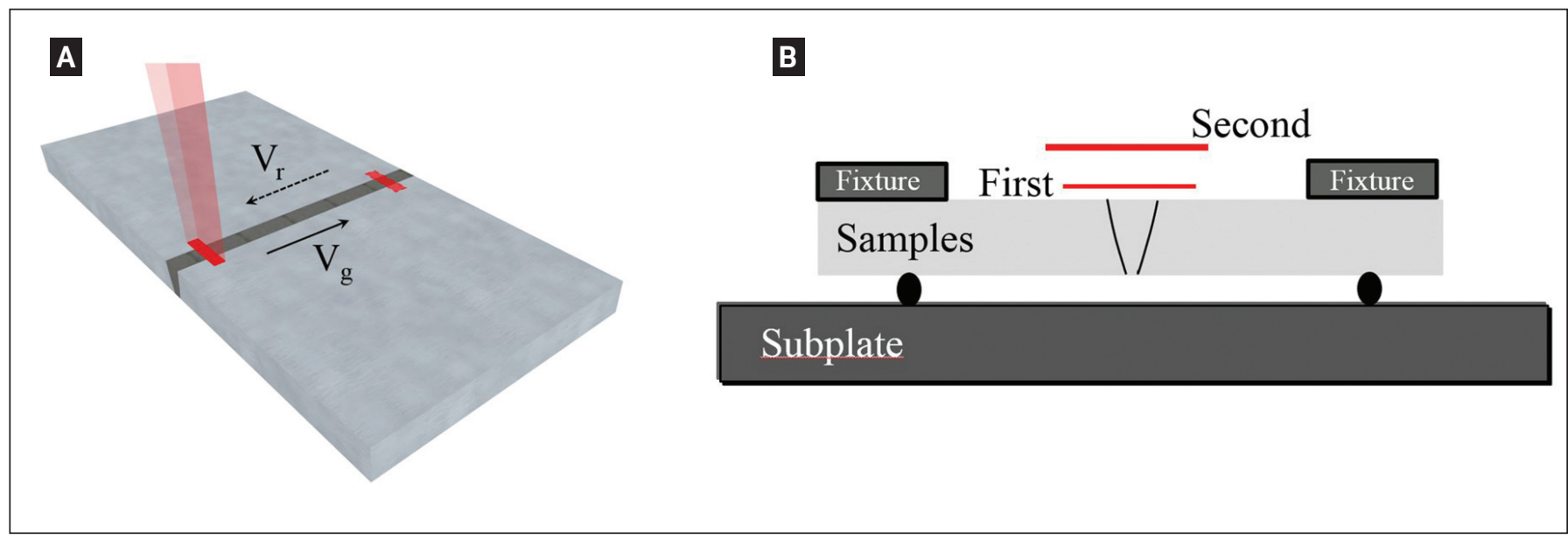

Fig. 2 - Schematic diagram of the LHT process: A - Scan path; B - installation diagram.

Table 1-Main Chemical Components of Base Metal (wt-\%)

\begin{tabular}{cccccccc}
$\mathrm{C}$ & $\mathrm{Mn}$ & $\mathrm{Cr}$ & $\mathrm{Mo}$ & $\mathrm{Ni}$ & $\mathrm{Si}$ & $\mathrm{Nb}$ & $\mathrm{Fe}$ \\
\hline 0.3 & 0.3 & 0.8 & 0.3 & 0.8 & 0.3 & 0.05 & other \\
\hline
\end{tabular}

Table 2 - The Main Parameters of the First LHT

\begin{tabular}{ccccc} 
Sample & Power $(\mathrm{W})$ & Speed $(\mathrm{mm} / \mathrm{s})$ & Defocusing Distance $(\mathrm{mm})$ & Scan Times (times) \\
\hline F-0 & 180 & 2 & +30 & 0 \\
F-1 & 180 & 2 & +30 & 3 \\
F-2 & 180 & 2 & +30 & 5 \\
\hline
\end{tabular}

The same IPG YLS-2000 fiber laser with an integral mirror was used for LHT. The principle of the integrating mirror is that, according to the geometrical optics, the traditional surface of revolution of the focal mirror is replaced by a multistrip curved surface of integrating mirror (Ref. 38). Therefore, after focusing of the integrating mirror, the laser beam would present the rectangular slit of light with uniform distribution of light intensity. The dimensions and light distribution of the spot are given in Fig. 1. A rectangular spot was produced with dimensions of about $4.0 \times 1.0 \mathrm{~mm}$, and the energy was uniformly distributed.

The schematic diagram of the LHT is shown in Fig. 2. As Fig. 2A indicates, the laser reciprocated along the weld in the range of $20 \mathrm{~mm}$ width to carry out local heating on the top surface of samples. Larger plates could be treated by scanning the surface with an overlap. As Fig. 2B shows, spacers were added between the samples and subplate to suppress heat dissipation.

To improve both the face- and the back-bending performance by single-face scanning, two stages of LHT (the first LHT and the second LHT) were performed. The first LHT was used to improve the back-bending property, while the second LHT was used to improve the facebending property of joints after the first LHT. Before LHT, black ink was applied as absorbent on the top surface of samples to increase the laser absorption rate. The effective constituent of black ink used in the study was carbon black. In the LHT process, the heat transfer could be controlled by different parameters, but no temperature measurement was employed for this investigation. The parameters of the two stages of the LHT process are given in Tables 2 and 3, respectively. It could be found that multipath laser scanning strategies were applied to obtain a high enough temperature. The F-0 samples in Table 2 refer to the laser-welded joints without LHT.

The microstructures of joints were observed with optical microscopy (OM) and scanning electron microscopy (SEM) combined with energy dispersive spectrometer (EDS). Before microstructure observation, the samples were sliced, polished, and etched with modified Fry's reagent $(50 \mathrm{~mL}$ $\mathrm{HCL}+25 \mathrm{~mL} \mathrm{HNO}_{3}+1 \mathrm{~g} \mathrm{CuCl}_{2}+150 \mathrm{~mL} \mathrm{H} \mathrm{H}_{2} \mathrm{O}$ ). Hardness measurements were performed on cross sections of joints using a Vickers hardness tester at $500 \mathrm{~g} / 15 \mathrm{~s}$. The test position was located at $0.15 \mathrm{~mm}$ from the face and back. Bending and tensile tests were performed. The sizes of test samples and the experimental device of bend are given in Fig. 3. It can be found that six times the punch diameter was used for the bending test. The bending test was performed according to the ISO 5173:2000 standard. The maximum bending angle was controlled at $90 \mathrm{deg}$. The weld reinforcement on the face and back regions was removed by manual grinding before the mechanical property tests. 


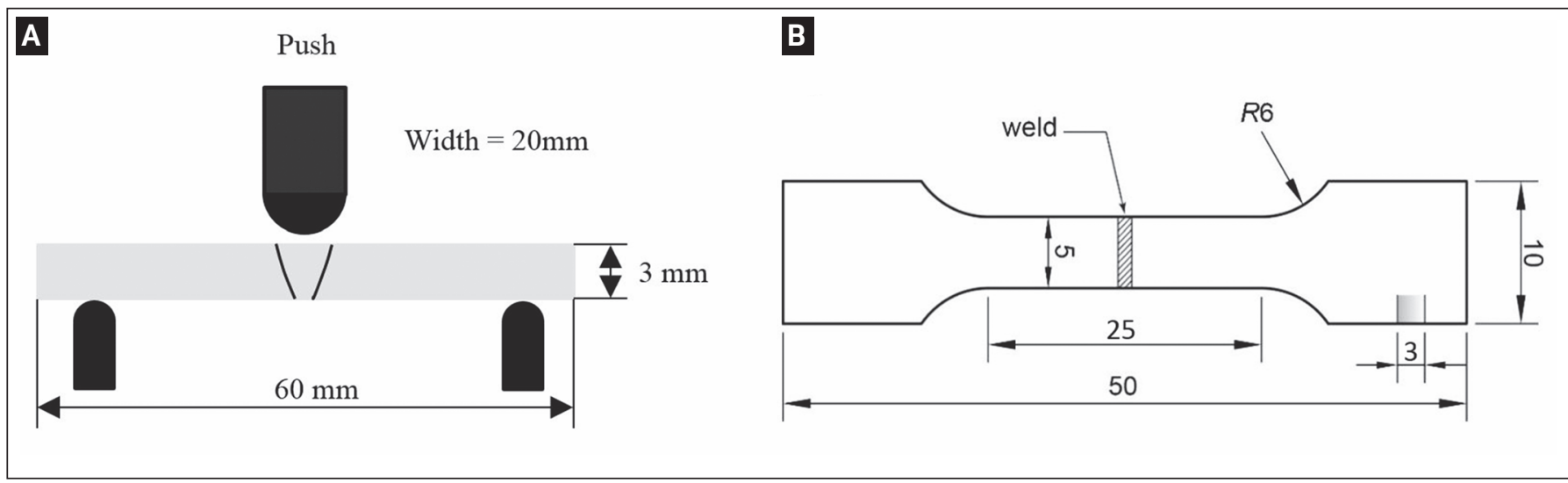

Fig. 3 - Sizes of test samples: A - Experimental device and sizes of bending samples; B - sizes of tensile samples.
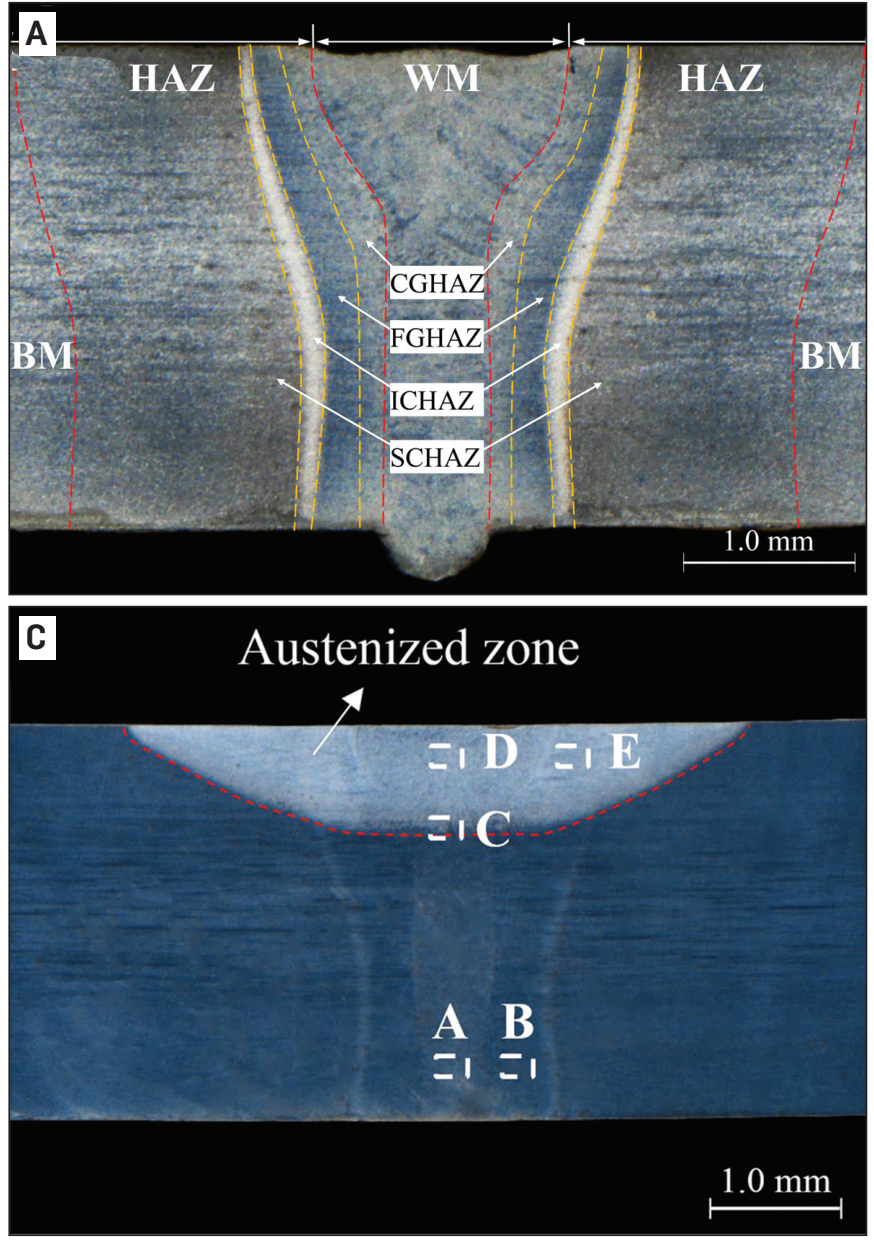

\section{Experimental Results}

\section{Microstructures and Hardness after the First Laser Heat Treatment}

Microstructures of joints. The OM micrographs of joints under different first LHT parameters are given in Fig. 4. The microstructures of laser-welded joints without LHT (F-0 joints) were presented in a previous work (Ref. 23). As Fig. 4A shows, the F-0 joints were composed of the WM and

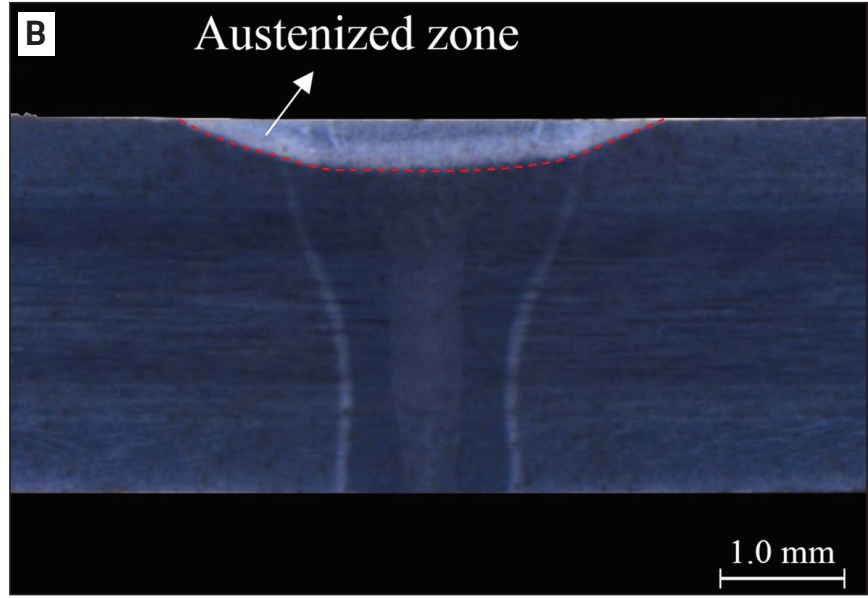

Fig. 4-Optical microscopy micrographs of joints under different parameters: $A-F-0$ joints; B $-F-1$ joints; $C-F-2$ joints.

HAZ. The HAZ can be divided into coarse-grained HAZ (CGHAZ), fine-grained HAZ (FGHAZ), intercritical HAZ (ICHAZ), and subcritical HAZ (SCHAZ). The microstructures in WM, CGHAZ, and FGHAZ are mainly lath martensite. The ICHAZ is composed of ferrite and martensite, and the microstructures in the SCHAZ are tempered martensite with ultrafine precipitated carbides.

As illustrated in Fig. 4B and C, the microstructures of joints were obviously affected by the first LHT. After the first LHT, the joints could be roughly divided into the austenized zone and the tempering zone. As the laser scanned around the upper surface where the temperature was higher, the austenized zone close to the face was presumably formed due to austenization. Additionally, the microstructures in the zone were significantly different with other zones. Since the laser spot was rectangular, the bowlshaped austenized zone (on cross section) with slant sides and flat bottom was formed. It was found that the greater austenized zone appeared in F-2 joints with lager heat input. According to the $\mathrm{Fe}-\mathrm{C}$ phase diagram, the part austenization occurs when the temperature is more than $\mathrm{Ac}_{1}$. So it can be speculated that the zones other than the austenized zone were treated with less than $\mathrm{Ac}_{1}$ temperature. Namely, the zones outside of the austenized zone were in the tempering range of temperature during the first LHT. 


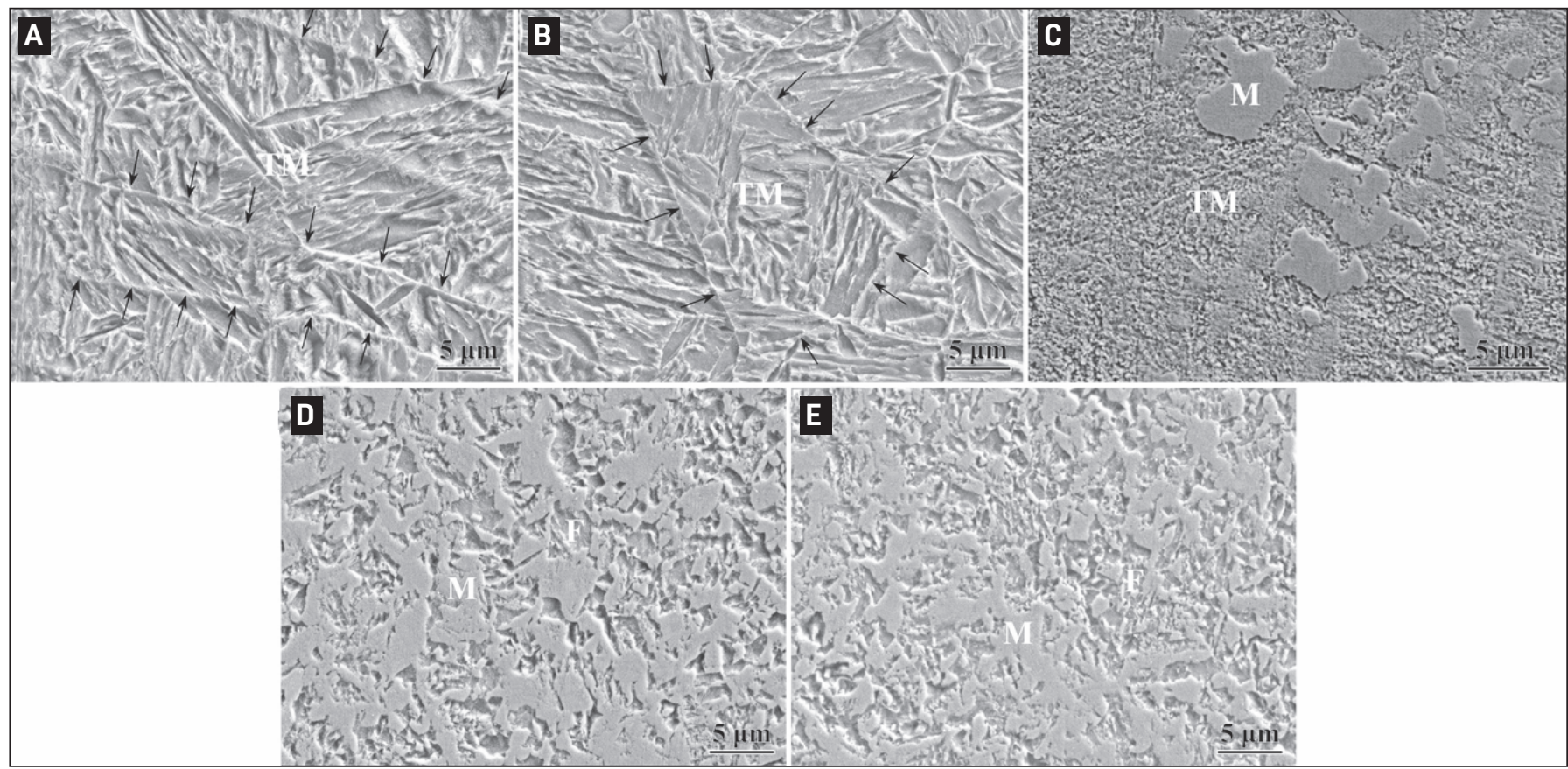

Fig. 5 - Scanning electron microscopy micrographs in different zones marked in Fig. 4C: A - WM at back; B - CGHAZ at back; C around boundary of the austenite zone; $D-W M$ in the austenite zone; $E-H A Z$ in the austenite zone.

The SEM micrographs in different zones marked in Fig. $4 \mathrm{C}$ are given in Fig. 5.

In the tempering zone, the original microstructures of the WM and HAZ before LHT were lath martensite. As shown in Fig. 5A and B, after the first LHT, the lath structure was still legible with a clear austenite boundary (marked by black arrows) in the WM and HAZ.

The high-magnification SEM micrographs of different zones are shown in Fig. 6. Corresponding micrographs of the WM and HAZ in the tempering zone are given in Fig. 6A and $\mathrm{B}$, respectively. There was almost no difference between the microstructural features of the WM and HAZ in the tempering zone. Large amounts of precipitates were found on the matrix of tempered martensite. Most of the precipitates were like short rods with sizes of $0.1 \sim 0.2 \mu \mathrm{m}$. Obvious precipitate aggregation was found. To identify the composition of the precipitates, cold field emission high-resolution SEM (Model: HITACHI SU8220) was used.

The surface distributions of different elements are illustrated in Fig. 7. As Fig. 7A shows, lots of precipitates can be clearly seen. It was found that the surface distributions of $C$ (seen in Fig. 7B) and Fe (seen in Fig. 7C) elements were uneven while the $\mathrm{Cr}$ (seen in Fig. 7D), Mn (seen in Fig. 7D), $\mathrm{Si}$ (seen in Fig. 7F), and $\mathrm{Ni}$ (seen in Fig. 7G) elements were well distributed, which indicates that the composition of precipitates has something to do with $\mathrm{C}$ and Fe instead of $\mathrm{Cr}, \mathrm{Mn}$, $\mathrm{Si}$, and $\mathrm{Ni}$. The stacking result of microstructures and distribution of the $\mathrm{C}$ element (seen in Fig. 7H) shows that the distributions of precipitates and $C$ were in good agreement. Figure 7I shows the element distributions of $C$ and Fe. It was found that the precipitates were a little rich in $C$ and had less Fe relative to the surrounding matrix.

Table 3 - The Main Parameters of the Second LHT

\begin{tabular}{ccccc} 
Sample & Power (W) & Speed (mm/s) & $\begin{array}{c}\text { Defocusing distance } \\
(\mathrm{mm})\end{array}$ & Scan times (times) \\
\hline S-1 & 120 & 2 & +50 & 4 \\
S-2 & 120 & 2 & +50 & 6 \\
\hline
\end{tabular}

Table 4- Mechanical Property Test Results of BM and Joints after the First LHT

\begin{tabular}{cccccc} 
Sample & Scan Times (times) & Back-Bending Angle (deg) & Face-Bending Angle (deg) & Tensile Strength (MPa) & Elongation (\%) \\
\hline BM & - & 180 & 30 & 180 & 1653 \\
F-0 & 0 & 50 & 28.5 & 1519 & 9.0 \\
F-1 & 3 & $>90$ & 37 & 5.3 & 1412 \\
F-2 & 5 & 62 & 1280 & 6.2 \\
\hline
\end{tabular}



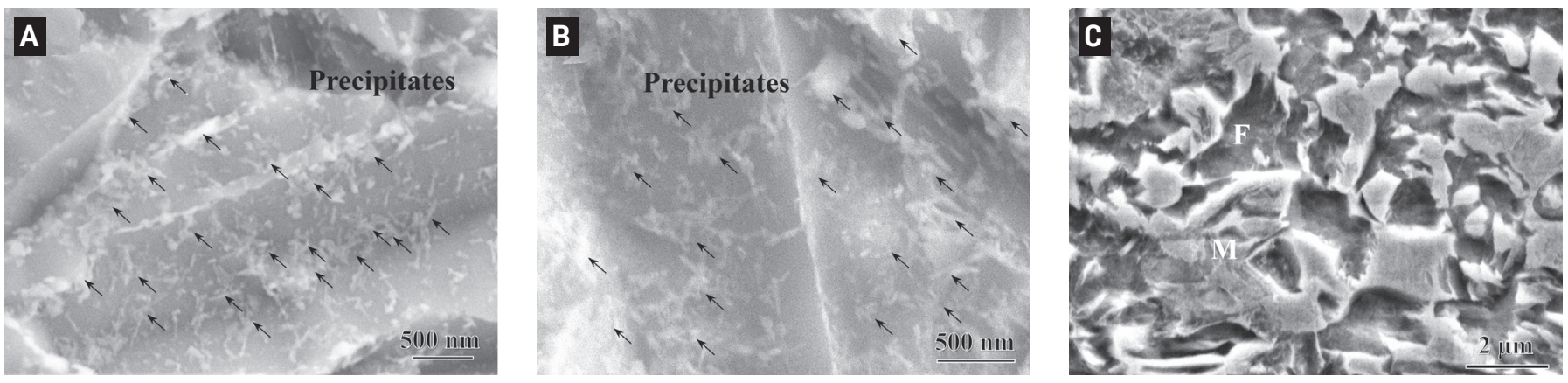

Fig. 6 - High-magnification SEM micrographs: $A-W M$ in the tempering zone; $B-C G H A Z$ in the tempering zone; $C-W M$ in the austenite zone.
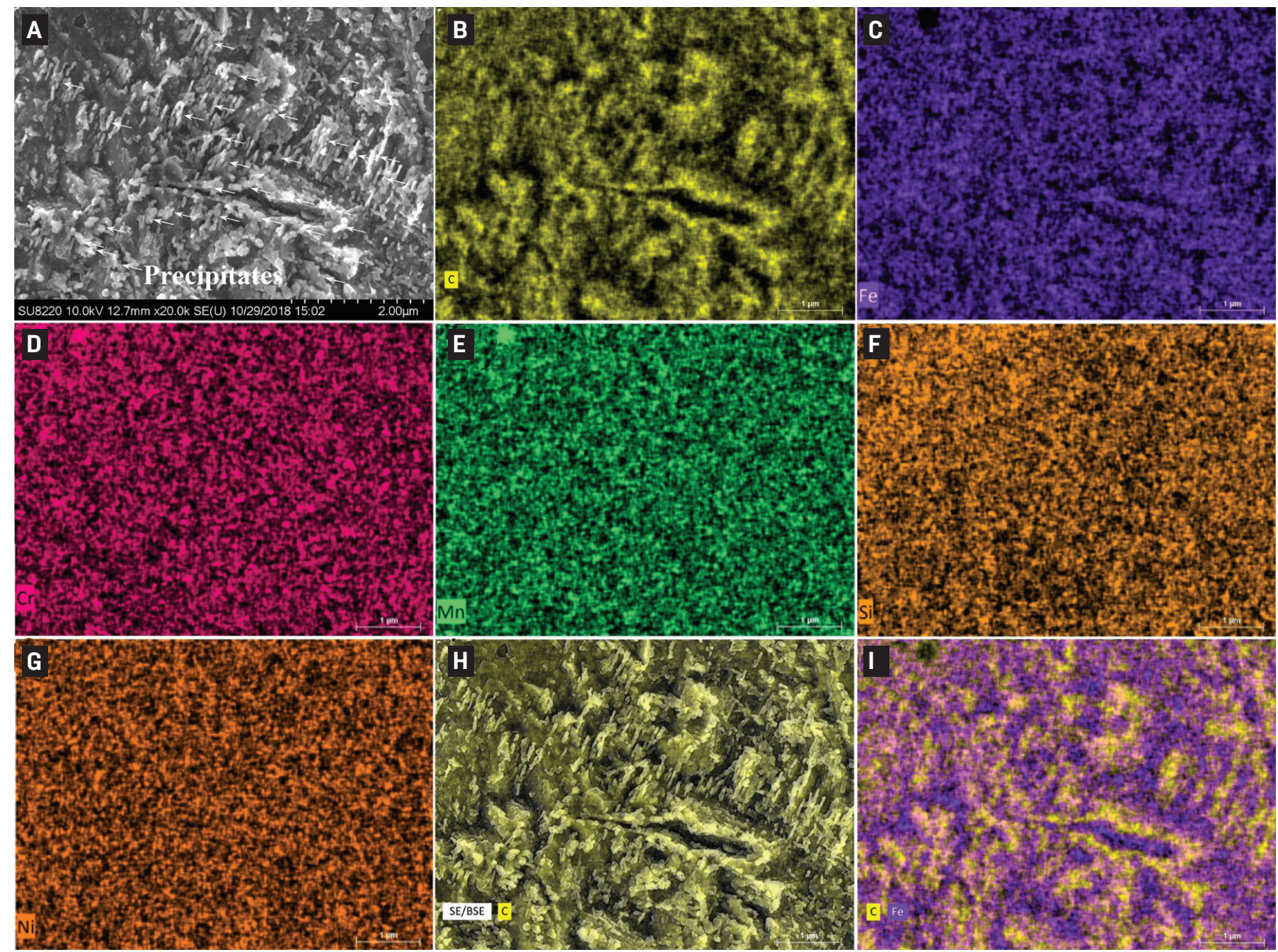

Fig. 7 - Surface distribution of different elements: A - Joint microstructures; B - distribution of C; $C-$ distribution of Fe; $D-$ distribution of $\mathrm{Cr}$; $\mathrm{E}$ - distribution of $\mathrm{Mn} ; \mathrm{F}$ - distribution of $\mathrm{Si} ; \mathrm{G}$ - distribution of $\mathrm{Ni}$; $\mathrm{H}$ - stacking distribution of microstructures and $\mathrm{C} ; \mathrm{I}$ - stacking distribution of $\mathrm{C}$ and Fe.

The austenized zone had a substantially different microstructure compared to the tempering zone. It was found that the original martensite was transformed into the dualphase structure, which may result from partial austenization during the first LHT. As indicated in Fig. 4B and C, it was difficult to distinguish between the welds and HAZ in the austenized zone, which implies that the microstructures of the whole zone were similar. As analyzed previously, the austenized zone was formed when the temperature was more than $\mathrm{Ac}_{1}$. Figure $5 \mathrm{C}$ shows the microstructures at the boundary of the austenized zone. It was found that the massive structure appeared on the tempered martensite matrix. As indicated in Fig. 5D and E, the microstructures of the 


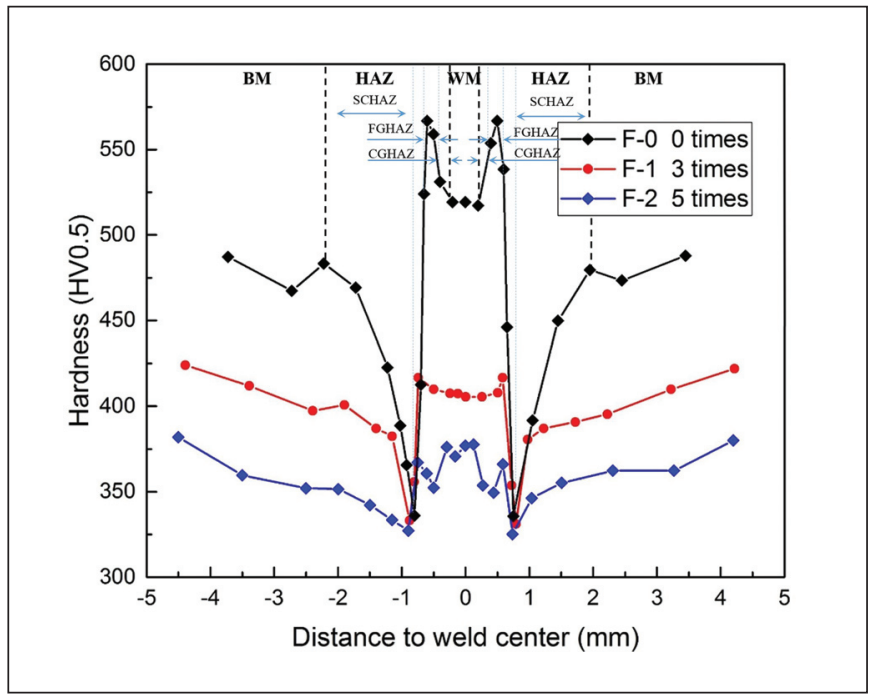

Fig. 8 - Microhardness distribution at the back of joints under the first LHT parameters.

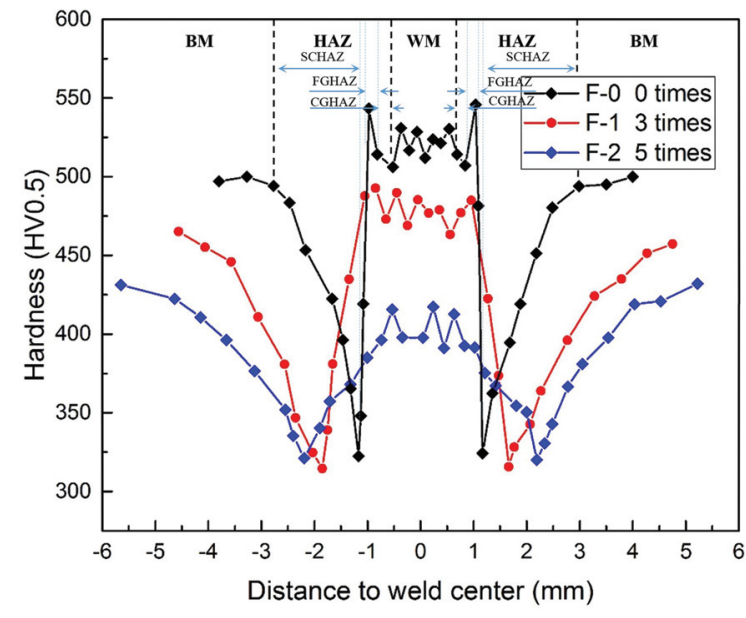

Fig. 9-Microhardness distribution at face of joints under the first LHT parameters.

Table 5-Mechanical Property Test Results of Joints After the Second LHT

\begin{tabular}{ccccc} 
Sample & Scan Times (times) & Face-Bending Angle (deg) & Tensile Strength (MPa) & Elongation (\%) \\
\hline S-1 & 4 & 78 & 1245 & 8.7 \\
S-2 & 6 & $>90$ & 1205 & 9.1 \\
& & & & \\
\hline
\end{tabular}

original WM and HAZ were similar, which consisted of two distinct phases. It was speculated that the massive structure in the dual-phase microstructures was martensite islands, and the other phase with polygonal morphology was ferrite. The high-magnification SEM micrographs of the WM in the zone are shown in Fig. 6C, which were mainly composed of dual-phase structures, and no obvious carbides were found. Presumably, most of the original precipitated carbides had dissolved in the austenite and supersaturated in the martensite. The existence of the austenized zone implies the heterogeneity of the mechanical property.

Microhardness of joints. The microhardness distributions at the back of joints under different parameters are given in Fig. 8. As illustrated in Fig. 8, the hardness of joints without LHT (F-0 joints) varied significantly. Similar distributions were published in a previous study (Ref. 23). The hardness of WM, CGHAZ, and FGHAZ was more than 520 $\mathrm{HV}$, higher than that of the base metal. A sharp decline occurred in the ICHAZ as ferrite appeared, which agrees with related reports (Ref. 5). The hardness in the zone decreased from $520 \mathrm{HV}$ to about $400 \mathrm{HV}$. The minimum hardness was obtained in the SCHAZ, close to the ICHAZ. The value in the zone was about $340 \mathrm{HV}$. The hardness gradually increased from the SCHAZ to the base metal as the peak temperature of the welding thermal cycle decreased. It can be found that the maximum hardness difference of the whole joints was about $240 \mathrm{HV}$, and distinct hardness valley existed in the soft zone, which presumably leads to poor bending property as a result of strain concentration.

As Fig. 8 shows, the hardness distributions at the back of joints after the first LHT tended to be more uniform, which implies that the first LHT was helpful in eliminating the joint's inhomogeneity. It was found that the hardness at the weld and the HAZ decreased overall while the minimum hardness at the SCHAZ remained about the same. This can be ascribed to the heating temperature at the back of joints during LHT, which may be in the range of tempering temperature but still less than $\mathrm{Ac}_{1}$. When the joints were treated three times (F-1 joints), the hardness around the weld metal was about $420 \mathrm{HV}$, far below the original $520 \mathrm{HV}$. Additionally, the hardness values of SCHAZ also dropped significantly except for the minimum value. The maximum hardness difference of the joints was about $100 \mathrm{HV}$. When the scan times were increased to five times (F-2 joints), the hardness of the whole joints decreased further and distributed more uniformly. The hardness difference was dropped to just about $50 \mathrm{HV}$.

The microhardness distributions at the faces of joints under different parameters are given in Fig. 9. Large scatters were noticed, indicating inhomogeneity of joints. As Fig. 9 indicates, for the joints without LHT (F-0 joints), the microhardness distribution at the faces was similar with that at the back of joints. The hardness valley was obvious. There were still huge differences of hardness even after the first LHT. For F-1 joints, the hardness around the center of the austenized zone was about $480 \mathrm{HV}$. The hardness value decreased gradually from the middle to the sides. The minimum hardness existed around the sides of the austenized zone, and the value was $340 \mathrm{HV}$, similar with F-0 joints. The hardness valley existed around the sides of the 


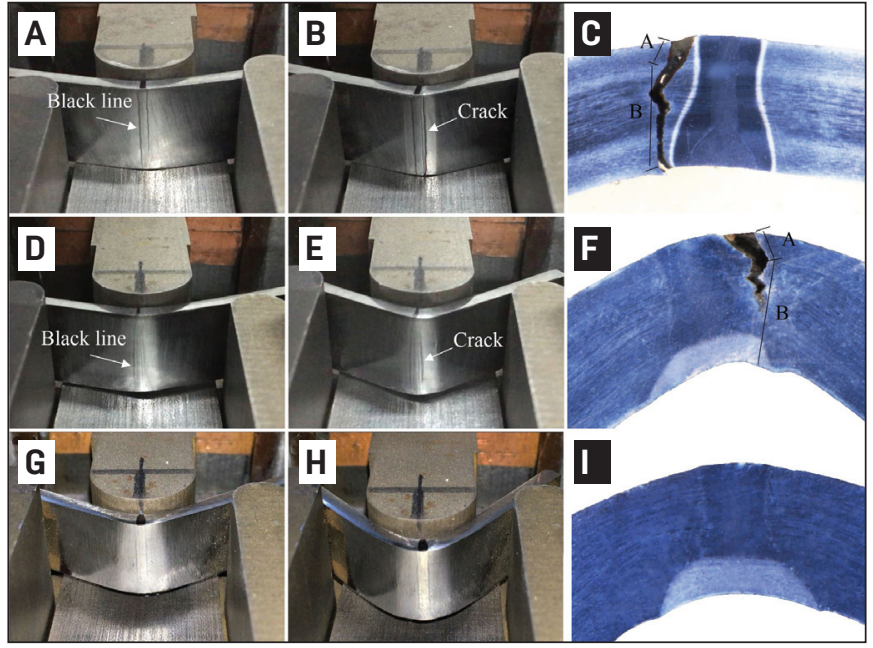

Fig. $10-$ Back-bending process and fracture sections of joints under the first LHT parameters: $A-C-F-0$ joints; $D-F-$ F-l joints; G-I - F-2 joints.
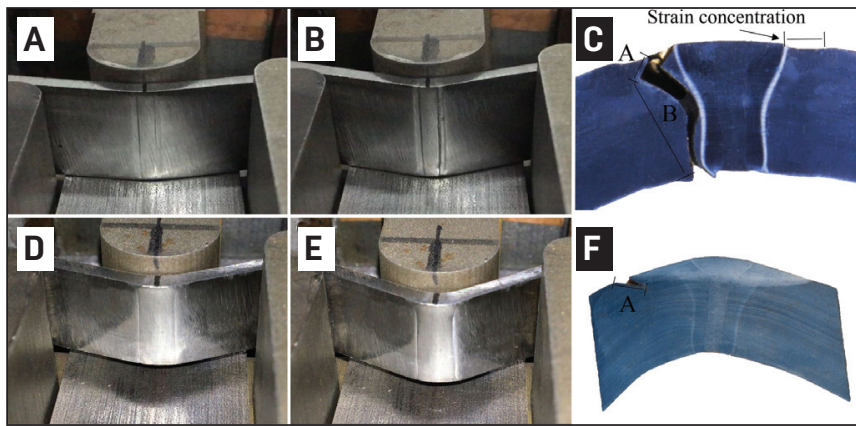

Fig. 12 - The face-bending process and fracture sections of joints under the first LHT parameters. A-C - F-0 joints; $D-F-$ F-2 joints.

austenized zone, which may limit the face-bending property of joints. For F-2 joints, the hardness distributions were similar to F-1 joints except for the value around the middle of the austenized zone. The hardness difference of the joints was still about $100 \mathrm{HV}$. When the scan times increased from three to five times, the austenized zone expanded and the hardness value around the middle reduced, which might be due to the fact that high heat input results in a larger affected zone and a shorter cooling rate.

\section{Mechanical Properties after the First Laser Heat Treatment}

The back-bending, face-bending, and tensile tests of the assupplied state of the base metal and joints under Table 2 parameters were carried out. The results are shown in Table 4.

Back-bending test results. The results indicate the maximum back-bending angle was varied under different parameters. For the joints without LHT (F-0 joints), the bending deformability was inadequate with only about a 30deg bending angle. After the LHT, the back-bending angle of joints improved significantly. For the joints scanned three times by laser (F-1 joints), the angle increased to about 50 deg. With the further increase of scan times to five times (F-

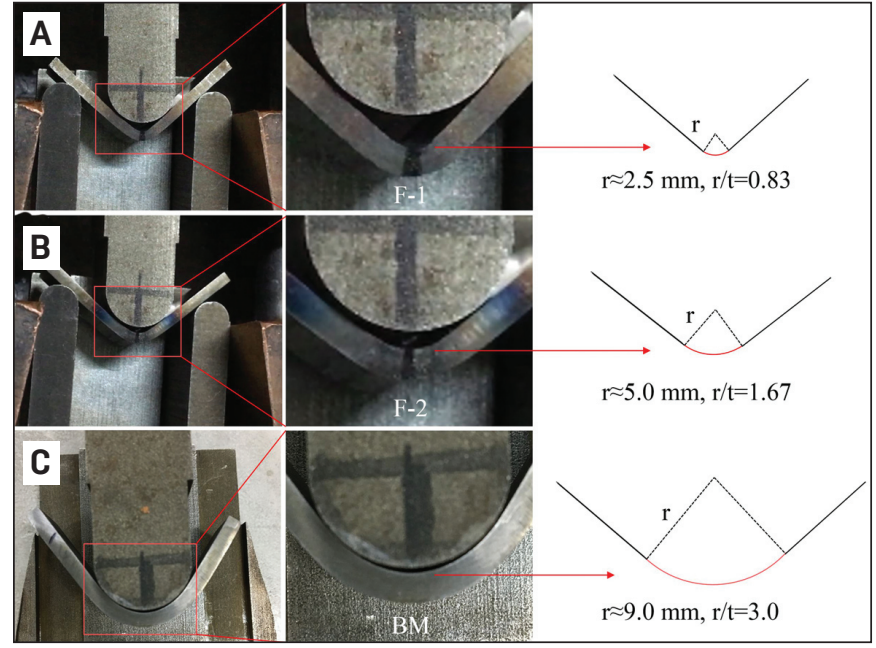

Fig. 11 - Joint appearances after the bending test: A - F-1 joints; $B-F-2$ joints; $C$ - base metal.

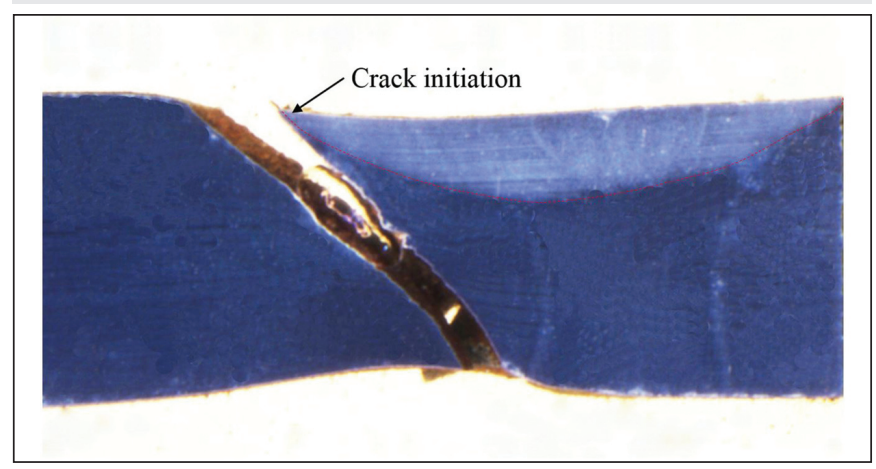

Fig. 13 - Fracture sections of F-2 joints after tensile testing.

2 joints), the more than 90-deg back-bending angle was obtained, which met the application requirements (Ref. 16). It indicates that the first LHT is an effective way to improve the back-bending property of joints.

The back-bending progress and fracture sections of the joints under different parameters are given in Fig. 10. As Fig. 10A and B show, for the joints without LHT (F-0 joints), black lines gradually appeared on both sides of the weld, and then the joints cracked along one of them, which might be due to the presence of strain concentration. Figure $10 \mathrm{C}$ indicates the F-0 joints fractured around the "black line." In the bending test, the major plastic deformation occurred at the surface where the material experienced the maximum tangential tensile stress. Therefore, the fracture may occur preferentially at the top of around the ICHAZ (seen in Fig. 10C) and then propagate around the zone since the corresponding hardness was the lowest. The fracture path can be divided into two parts: rapid expansion zone and slow expansion zone. After it initiated at the top surface of around the ICHAZ, the crack expanded rapidly along a line (path A) to release the energy accumulated in the early stage. Then the crack expanded slowly (path B) with the further movement of the bending punch. The path was inclined to the ICHAZ since the hardness decreased gradually close to the ICHAZ. Finally, the samples ruptured completely in the SCHAZ. The bending progress and fracture sections of F-1 joints are 


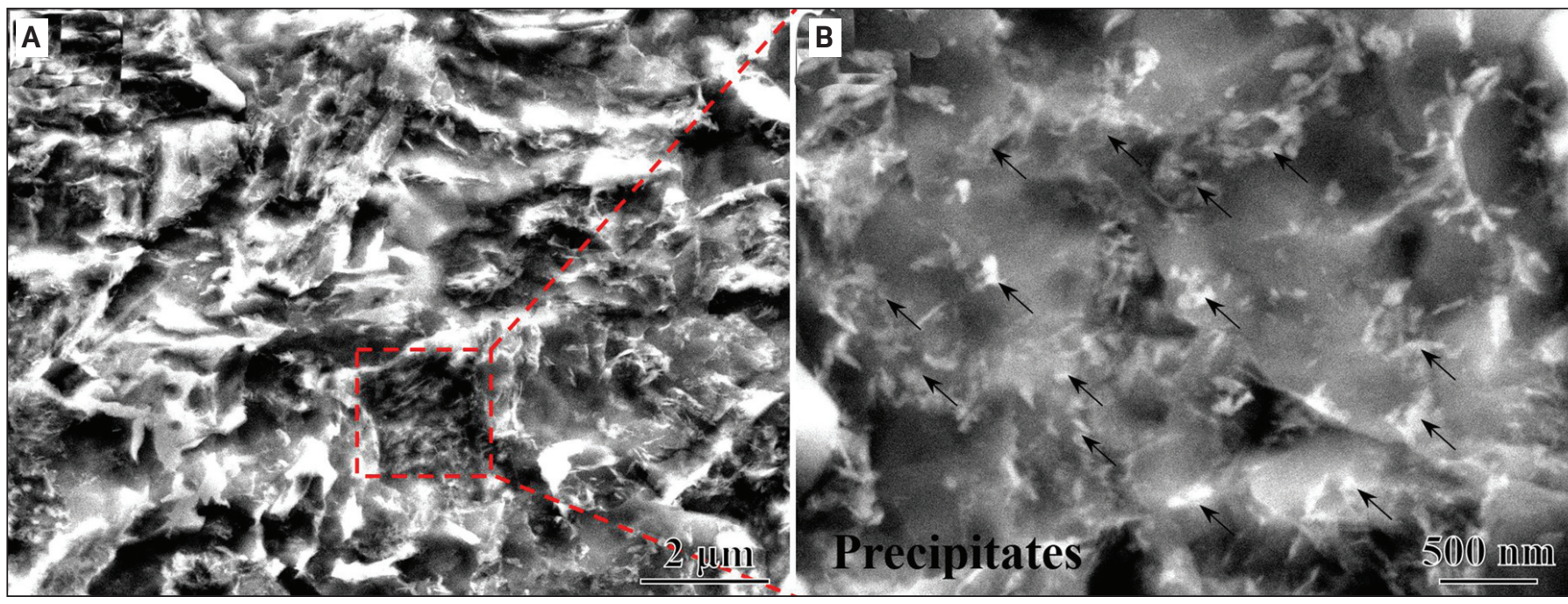

Fig. 14 - SEM micrographs of the austenite zone after the second LHT (S-2 joints): A - 0-k magnification; B - 30-k magnification.

shown in Fig. 10D-F. It was found that a similar phenomena happened, but the black lines were not so obvious with the same angle. A wider bending angle was obtained, and the joints finally failed in the same position. The fracture path was also similar to the F-0 joints since the changing law of hardness is the same. The crack also initiated around the top surface and expanded along paths A and B. As Fig. 10G and $\mathrm{H}$ show, no obvious strain concentration appeared on the F2 joints, and a more than 90-deg bending angle was obtained successfully without obvious cracks on the joint's surface (seen in Fig. $10 \mathrm{H}$ and I).

The relative bending radius is the ratio of the inner radius $r$ of the bending sample to the plate thickness $t$. The joint and base metal appearances after the bending test are given in Fig. 11. It was found that there exists obvious differences in the relative bending radius under different LHT parameters. As Fig. 11A shows, the bending radius of F-1 joints was significantly smaller than the bending punch radius to leave a lot of space between samples and the punch. Measured based on the geometric method, the average inner radius of F-1 joints was about $2.5 \mathrm{~mm}$, and the relative bending radius was just about 0.83. As Fig. 11B shows, for F-2 joints, the fit situation of F-2 joints between the samples and bending punch improved to some extent. The inner radius was about $5.0 \mathrm{~mm}$ and the relative bending radius was about 1.67 . As Fig. $11 \mathrm{C}$ illustrates, the base metal bending samples stayed close to the bending punch, and a good fit was achieved. The bending radius was about $9.0 \mathrm{~mm}$, basically the same as the radius of the punch. The relative bending radius was 3.0.

Face-bending test results. The face-bending results of joints under different parameters are shown in Table 4. It should be noted that the face-bending angles were still unsatisfactory after the first LHT. For the joints without LHT, the angle was just about $28.5 \mathrm{deg}$, similar with the back-bending angle. After LHT, the angle was improved. With three scan times, the face-bending angle of joints (F-1 joints) increased slightly to $37 \mathrm{deg}$. With the further increase of scan times to five times (F-2 joints), the face-bending angle increased to 62 deg. The improvement of face-bending angle was in good agreement with hardness distributions at the face of joints

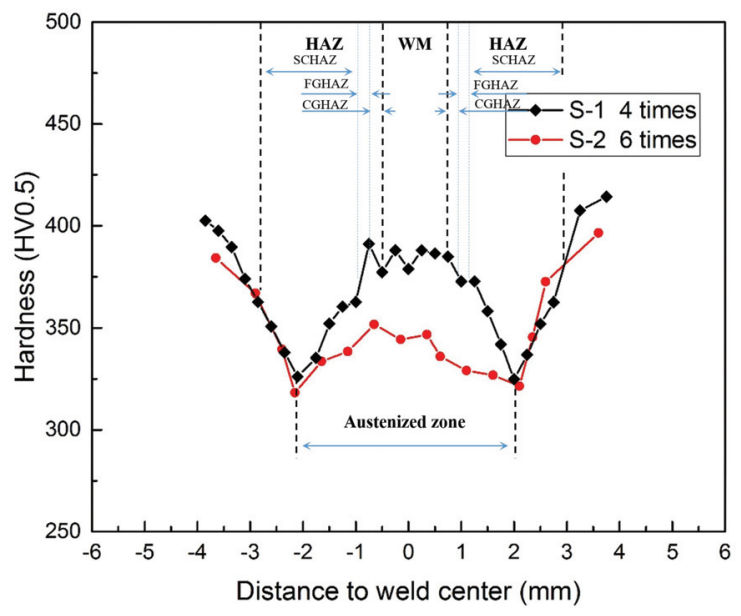

Fig. 15 - Microhardness distribution at the face of joints under the second LHT parameters.

(seen in Fig. 9), which tend to be more uniform after the first LHT. However, as shown in Fig. 9, the hardness valley still exists even after five scan times, which cannot be eliminated by the optimizing of the first LHT. This would limit the facebending property of joints. Namely, the face-bending property was not satisfactory after the first LHT.

The bending process and fracture sections of the joints under different parameters are shown in Fig. 12. As illustrated in Fig. 12A-C, just like the back bending, the black lines also appeared as a result of strain concentration. The plastic deformation zone can be clearly seen in the figures while the weld metal deformed a little. The fracture sections (seen in Fig. 12C) indicate that the strain concentration zone was located in the SCHAZ where the hardness was less compared to other zones. The black lines were close to the ICHAZ. The fracture process was also composed of the rapid expansion phase (phase A) and slow expansion phase (phase B).

For F-1 joints, plastic deformation also concentrated, and the crack initiated at the boundary of the austenized zone instead of around the original ICHAZ (seen in Fig. 12D-F) 


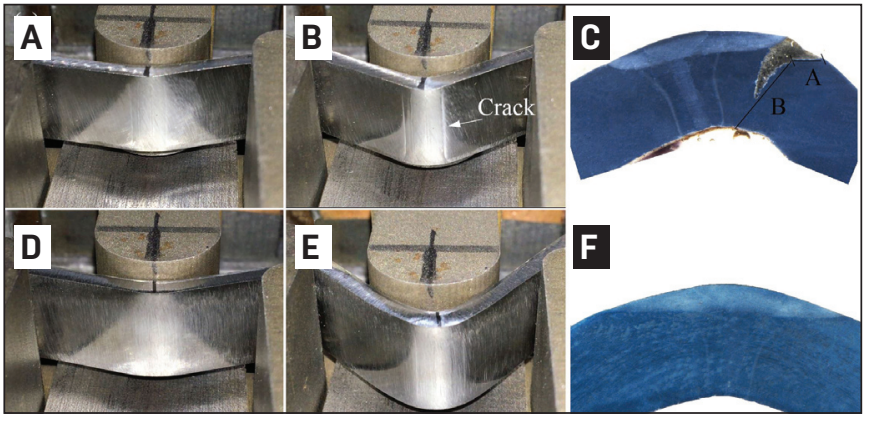

Fig. 16 - The face-bending process and fracture sections of joints under the second LHT parameters: A-C - S-1 joints; $D-F-S-2$ joints.

as the minimum hardness appeared in the sides of the austenized zone, which is consistent with hardness distribution. A similar phenomenon happened during the face bending of F-1 joints. Namely, the first LHT would limit the face-bending property of joints, and the second LHT was needed to solve the problem.

Tensile test results. The tensile test results of joints after the first LHT are given in Table 4, which reveal a substantial influence of LHT on mechanical properties. For base metal samples with the sizes shown in Fig. 3B, the tensile strength was approximately $1653 \mathrm{MPa}$ with the elongation of $9.0 \%$. In the untreated state, the F-0 joints had tensile strength of approximately $1519 \mathrm{MPa}$ and showed a joint efficiency of more than $93.0 \%$. As Table 4 shows, the tensile strength of joints decreased gradually with the increase of scan times, which means the first LHT weakened the laserwelded joints. For F-1 joints, the tensile strength was about $1412 \mathrm{MPa}$. With the further increase of scan times to five times, the tensile strength reduced to $1280 \mathrm{MPa}$. This may result from the increase of heat input, but the strength still stayed far above $1000 \mathrm{MPa}$ of arc-welded joints. Namely, the LHT could minimize strength loss of joints.

In the untreated state, the F-0 joints showed a low homogeneous plastic deformation with a total elongation of about $5.3 \%$. In comparison, the joints after LHT showed a larger range of homogeneous plastic deformation. The F-1 joints had an elongation of about $6.2 \%$, and the F-2 joints showed an elongation of $8.5 \%$. It can be concluded that the LHT was beneficial to the formability of joints. The results agreed well with findings of correlational research (Ref. 30).

The fracture sections of F-2 joints after tensile testing are given in Fig. 13. It can be found that the fracture path was a 45-deg bevel, which is close to the austenized zone. Therefore, it was suspected that the fracture might initiate at the edge of austenite since the hardness around the zone is the lowest. The crack then extended along the 45-deg shear plane and finally broke off. Namely, the existence of a softened zone in the circumferential austenized zone weakened and limited the strength of joints.

\section{Microstructures and Hardness after the Second Laser Heat Treatment}

After the first LHT, the second LHT was employed to improve the face-bending property of joints. To obtain satisfac-

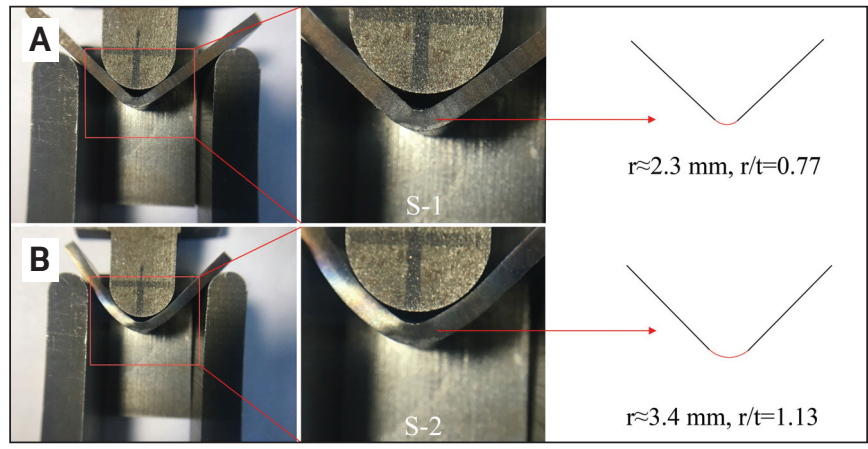

Fig. 17 - Joint appearances after the bending test: $A-S-1$ joints; B $-S-2$ joints.

tory face- and back-bending angles, all the second LHT were adopted based on F-2 joints. Lower power was used in the second LHT to soften the austenized zone instead of the tempering zone. Since the tempering zone was almost unaffected, observation and hardness testing for the microstructures were only performed on the austenized zone.

Microstructures of joints. The SEM micrographs of joints after the second LHT (S-2 joints) are given in Fig. 14. As Fig. 14A shows, the zone kept the original dual-phase microstructures with visible precipitates. Through the highmagnification micrographs in Fig. 14B, the precipitates were like short rods with sizes of $0.1 \sim 0.2 \mu \mathrm{m}$, just like the precipitation carbides in the tempering zone after the first LHT. It was speculated that similar microstructure transformation occurred in the austenized zone after the second LHT.

Microhardness of joints. The microhardness distributions of joints after the second LHT are illustrated in Fig. 15. The ranges of the austenized zone and original subzones of the weld were marked in the figure. It can be seen that, after the second LHT, the hardness in the austenized zone reduced while the values outside basically kept invariant. For S-1 joints, the hardness around the center of the austenized zone decreased to about $385 \mathrm{HV}$. As the original minimum hardness remained unchanged, the hardness difference reduced to $60 \mathrm{HV}$ and the hardness valley still existed, which may limit the deformability of joints. With the increase of scan times to six times (S-2 joints), the hardness in the middle of the austenized zone decreased to $345 \mathrm{HV}$, and the different value reduced to $20 \mathrm{HV}$. This means that the steep hardness gradient beneath the face was completely smoothed out to a similar hardness.

\section{Mechanical Property after the Second Laser Heat Treatment}

As the second LHT was performed based on F-2 joints with less power, it was speculated that the back-bending angle was wide enough after the second LHT. Therefore, only the face-bending and tensile tests of joints under Table 3 parameters were carried out. The results are given in Table 5 .

Face-bending test results. For the joints scanned four times by the second LHT (S-1 joints), the face-bending angle of joints was improved 62-78 deg. With the scan times increasing to six times (S-2 joints), the bending deformability was further improved, and a more than 90-deg face-bending 
angle was obtained. Namely, the second LHT could effectively improve the face-bending property of the joints.

The face-bending process and fracture sections under different parameters are shown in Fig. 16. As illustrated in Fig. $16 \mathrm{~A}$ and $\mathrm{B}$, for $\mathrm{S}-1$ joints, the strain concentration around the side of the austenized zone still existed and finally resulted in cracking, which was similar to the process of F-2 joints. However, the corresponding angle was significantly wider. As shown in Fig. 16C, compared to F-2 joints, the weld metal and austenized zone of S-1 joints had been greatly deformed before the crack. Presumably, the softened austenized zone participated in the bending deformation but finally still failed around the sides of the austenized zone with a similar fracture path. For S-2 joints, a more than 90-deg angle was obtained without cracking (seen in Fig. $16 \mathrm{D}$ and $\mathrm{E}$ ), and no obvious plastic deformation concentration was observed. As seen in Fig. 16F, the austenized zone deformed significantly with the extension in the circumferential direction and thinning in the radial direction.

The appearances of S-1 and S-2 joints after the bending test are given in Fig. 17. Compared with S-2 joints, there was more space between samples and the punch, which implied a smaller inner radius during the bending test. As Fig. 17A shows, the average inner radius of $S-1$ joints was just about $2.3 \mathrm{~mm}$, and the relative bending radius was about 0.77 . For the S-2 joints (seen in Fig. 17B), the inner radius was about $3.4 \mathrm{~mm}$, and the relative bending radius was about 1.13 .

Tensile test results. The tensile test results after the second LHT can also be found in Table 5. As illustrated in the table, little strength loss occurred after the second LHT. For the joints with four scan times (S-1 joints), the tensile strength reduced to $1245 \mathrm{MPa}$. With the increase of scan times to six times ( $\mathrm{S}-2$ joints), the strength decreased to $1205 \mathrm{MPa}$ with about 73\% joining efficiency. Meanwhile, the elongation was improved from 8.7 to $9.1 \%$. Namely, the second LHT further compromised the tensile strength of joints. However, the reduction was less as the weakness zone of joints had already formed after the first LHT. The strength of joints after the second LHT was still significantly higher than the $1000 \mathrm{MPa}$ of the arc-welded joints.

\section{Discussion}

\section{Homogenization of Microstructure and Hardness Distribution of Joints}

Homogenization of the microstructure happened in different zones of joints after the LHT. Based on the results of microstructures of joints after the first LHT, it was inferred that the tempering transformation of martensite occurred in the tempering zone. The element distributions in Fig. 7 indicates that the composition of the precipitates is related to $C$ and Fe. Based on relevant references (Refs. 39, 40), the transformation temperature of $\varepsilon$-carbide to cementite is about $260^{\circ} \sim$ $310^{\circ} \mathrm{C}$ in low-alloy steel. The precipitated phase in the martensite is mainly $\varepsilon$-carbide when the tempering temperature is less than $260^{\circ} \mathrm{C}$. When the tempering temperature reaches $260^{\circ} \sim 310^{\circ} \mathrm{C}$, the precipitated $\varepsilon$-carbide in the martensite transforms to cementite. Therefore, it is speculated that the

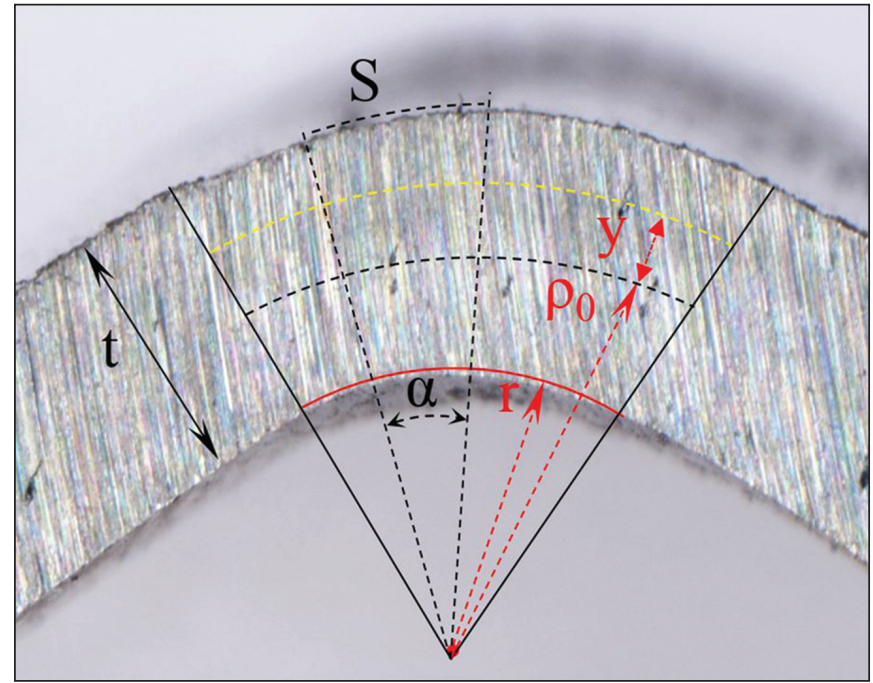

Fig. 18 - Geometrical relationship of bending samples.

precipitates are cementite, which is composed of rich C (6.67wt-\%, theoretical content in cementite) and poor $\mathrm{Fe}$ (93.33 $\mathrm{wt}-\%$, theoretical content in cementite) compared to the average element content of the base metal. This inference corresponds well to the results of reported works (Refs. 40, 41). The precipitation of cementite is a typical characteristic of martensite tempering. In the tempering process, the carbon supersaturated in martensite precipitates in the form of carbides, and then the original martensite was decomposed into ferrite and carbides (Ref. 41). The carbides aggregated and grew with the high-tempering temperature (Refs. 42, 43).

In the austenized zone, massive microstructures appeared after the first LHT. Based on analysis of the formation mechanism (Ref. 44) and morphology (Refs. 41, 45), the structures were judged to be martensite islands, which generally contain a lathy substructure (Refs. 41, 46). It is supposed that partial austenization occurred during LHT, and the precipitated carbides started to dissolve into the austenite. After cooling, the austenite transformed into martensite and the ferrite was retained. Close to the face, the peak temperature rose gradually, which led to the increase of fresh martensite. Therefore, the dual-phase microstructures in the austenized zone were martensite islands and polygonal ferrite. Presumably, most of the original precipitated carbides of joints had dissolved in the austenite and supersaturated in martensite. Therefore, after the second LHT, the carbide precipitated again from the martensite. As Fig. 14 shows, for the joints after the second LHT, the precipitates in the austenized zone were similar with the precipitation in tempering zone. It is speculated the precipitates in the austenized zone were also cementite. Namely, the dual-phase microstructures in the austenized zone were tempered after the second LHT. Therefore, the LHT mitigated the microstructural difference of joints since the microstructures in different zones converted to the tempered structure after two stages of laser heat treatment.

The homogenization of the microstructure inevitably had an effect on the hardness distribution of joints. According to a previous study (Ref. 23), the minimum hardness of joints resulted from high-temperature tempering of the SCHAZ. A similar phenomenon occurred around the side of the aust- 
enized zone after the first LHT. As shown in Figs. 8, 9, and 15, the minimum hardness at the face and back of joints changed little after the LHT. Since the LHT led to the overall tempering evolution in different zones of joints, the hardness distribution inevitably reduced. As shown in Fig. 8, the hardness difference at the back of joints decreased from 240 to $50 \mathrm{HV}$ after the first LHT. The hardness valley was not so conspicuous. A similar phenomena also occurred in the austenized zone. As shown in Figs. 9 and 15, the hardness difference at the faces of joints reduced from 100 to $20 \mathrm{HV}$ after the second LHT. Namely, the hardness evenly distributed after the two stages of laser heat treatment, which implies a mechanical homogeneity. It can be concluded that the LHT is helpful for uniform mechanical properties at the back and face of joints.

\section{Influence Mechanism of LHT on the Bending Property of Joints}

According to the test results of the mechanical property, the obvious local hardness valley led to significant strain concentration in the corresponding zone, which resulted in the poor bending property. For the joints after LHT, there existed uniform microstructures and hardness in the local zone, and no obvious strain concentration occurred during bending to more than $90 \mathrm{deg}$. Therefore, the influence mechanism of LHT on the bending property of joints needs to be further studied.

The geometrical relationship of bending samples is illustrated in Fig. 18. The mathematic relation between arc lengths and bending radius is shown in Equation 1 (Ref. 47).

$$
S=\frac{\pi(r+t) \alpha}{180}
$$

where $r$ is the bending radius at the inner surface of the samples; $t$ is the thickness of the samples; $\rho_{0}$ is the radius of the neutral layer; $\alpha$ is the angle of the circumference; and $S$ is the arc length of the bending-deformation zone.

It can be derived based on Equation 1 that the $r$ would decrease with the decrease of $S$ under the same $\alpha$. For the joints with the obvious local hardness valley, the plastic deformation mainly located in the local area instead of dispersed distribution in the large zone. Therefore, the corresponding bending radius $r$ and the relative bending radius $r / t$ presumably would be small.

This inference is consistent with the phenomenon observed in Fig. 11. For F-1 joints, the bending-deformation zone was basically limited to around the hardness valley. The relative bending radius was minimal, just about 0.83 . For F-2 joints, the bending-deformation zone further expanded to the WM and the original lower temperature SCHAZ as the inhomogeneity of joints was partially eliminated by the LHT. The relative bending radius of the joints had increased to 1.67. For the base metal, the bending-deformation zone was not limited by the inhomogeneity of samples since the microstructure and mechanical property were uniform. Therefore, the base metal bending samples had the maximum relative bending radius. As shown in Fig. 17, the situation was similar for face-bending joints under different parameters. Compared with S-2 joints, S-1 joints had less $r / t$ and a bigger space between the samples and bending punch.

The relative bending radius had a significant effect on tensile stress at the outside surface of the bending samples. Logarithmic strain in the cross section of sheet metal was described as in Equation 2 (Ref. 48).

$$
\varepsilon=\frac{y}{t} \ln \left(1+\frac{t}{r}\right)
$$

where $\varepsilon$ is the circumferential strain in the cross section during the bending test, and $y$ shows an arbitrary position in a certain radius direction. When $y$ is equal to $t / 2$, the $\varepsilon$ is the strain at outside surface of the bending samples. Hollomon's power hardening law was generally used for the description of constitutive equation of LAUHSS (Ref. 49), and the stress-strain relationship is shown in Equation 3.

$$
\sigma=K \bullet \varepsilon^{n}
$$

where $\sigma$ is the true stress, $K$ is the strength coefficient, and $n$ is the strain hardening exponent. From Equations 2 and 3, the circumferential stress at the outside surface of the bending samples is calculated by Equation 4 .

$$
\sigma=K \cdot\left(\frac{1}{2} \ln \left(1+\frac{t}{r}\right)\right)^{n}=\frac{K}{2^{n}}\left(\ln \left(1+\frac{t}{r}\right)\right)^{n}
$$

It can be found that the tensile stress on the bending surface $\sigma$ generally increases as the relative bending radius decreases. For the bending test, since the F-1 joints and the $S$ 1 joints have the lower relative bending radius, it can be speculated that the tensile stress of the corresponding zone is higher, which may be the reason why the joints fractured during the test. With the increase of a relative bending radius, the lateral tensile stress gradually decreases, which is beneficial for the improvement of bending performance. Therefore, F-2 joints and S-2 joints could achieve more than a 90-deg bending angle.

\section{Conclusion}

Two stages of laser heat treatment were proven to be effective in the improvement of the face- and back-bending property of laser-welded LAUHSS joints. Based on the results achieved in this study, the following conclusions were obtained.

1) After the first LHT, the joints can be roughly divided into two regions: austenized zone near the face and tempering zone near the back. In the tempering zone, the original inhomogeneous microstructures in the weld metal and HAZ transformed into homogeneous tempered martensite with precipitated carbides, which led to the results that the original steep hardness gradient at the back was smoothed out to similar hardness. In the austenized zone, austenization occurred and the original martensite was transformed into a F-M dual-phase structure. Meanwhile, high-temperature tempering occurred around the boundary of the austenized zone. The hardness distributions at the faces of the joints revealed that there were large scatters of hardness, and the hardness valley existed around the sides of the austenized 
zone. The mechanical property test results showed that the back-bending property of laser-welded joints could be improved by the first LHT. More than a 90-deg back-bending angle with $1280 \mathrm{MPa}$ tensile strength was obtained. However, the face-bending angle was about $37 \sim 62 \mathrm{deg}$, which is still unsatisfactory.

2) The second LHT was performed to improve the facebending property of joints after the first LHT. Lower power was used in the second LHT to soften the austenized zone with less effect on the back-bending property. The dualphase microstructures in the austenized zone tempered, and similar carbides precipitated. The hardness distribution of joints after the second LHT tended to be more uniform, and the hardness valley around the austenized zone disappeared. A more than 90-deg face-bending angle was obtained with $1205 \mathrm{MPa}$ tensile strength.

3) Strain concentration has significant effects on the bending property of joints. After LHT, the range of plastic deformation during the bending process expanded instead of concentrating in the hardness valley zone, which would lead to a larger relative bending radius. The tensile stress on the bending surface decreased with the increase of the relative bending radius. Therefore, it is speculated that the tensile stress would be less after LHT, and this would be beneficial for the improvement of bending performance.

\section{Acknowledgments}

This project is supported by the National Natural Science Foundation of China (grant no. U1537205). The authors would like to express their appreciation to the researchers who gave their assistance to this study.

\section{References}

1. Xie, Z. J., Shang, C. J., Wang, X. L., et al. 2018. Microstructure-property relationship in a low carbon $\mathrm{Nb}-\mathrm{B}$ bearing ultra-high strength steel by direct-quenching and tempering. Materials Science and Engineering A 727(6): 200-207. DOI: 10.1016/j.msea.2018.04. 086

2. Wen, C., Wang, Z., Deng, X., et al. 2018. Effect of heat input on the microstructure and mechanical properties of low alloy ultrahigh strength structural steel welded joint. Steel Research International 89(6): $1700500-1$ to $1700500-9$. DOI: $10.1002 /$ srin. 201700500

3. Erdem, M., Mehmet, A., and Karabulut, M. 2016. Investigation of mechanical, microstructural, and machining properties of AISI 420 martensitic stainless steel welded by laser welding. International Journal of Advanced Manufacturing Technology 85(1-4): 481-492. DOI: 10.1007/s00170-015-7924-2

4. El-Batahgy, A. M., Miura, T., Ueji, R., and Fujii, H. 2016. Investigation into feasibility of FSW process for welding $1600 \mathrm{MPa}$ quenched and tempered steel. Materials Science and Engineering A 651: 904-913. DOI: 10.1016/j.msea.2015.11.054

5. Janicki, D. 2014. Disk laser welding of armor steel. Archives of Metallurgy and Materials 59(4): 1641-1646. DOI: 10.2478/ amm-2014-0279

6. Pek, N. E., and Elaldi, F. 2012. Analysis of welding groove angle and geometry on strength of armor steel. Materials and Manufacturing Processes 27(12): 1437-1441. DOI: 10.1080/10426914. 2012. 709343
7. Hanhold, B., Babu, S. S., Cola, G. M., and Ream, S. 2012. Investigation of HAZ softening in laser welding of AHS/high hardness steels. $9^{\text {th }}$ International Conference on Trends in Welding Research, American Society for Metals, pp. 19-25. Chicago, Ill. ASM International.

8. Murthy, N. K., Ram, G., and Murty, B. S. 2014. Carbide-free bainitic weld metal: A new concept in welding of armor steels. Metallurgical \& Materials Transactions B 45(6): 2327-2337. DOI: 10.1007/s11663-014-0120-1

9. Magudeeswaran, G., Balasubramanian, V., and Balasubramanian, T. S. 2013. Effect of welding consumables on tensile and impact properties of shielded metal arc welded high strength, quenched and tempered steel joints. Science \& Technology of Welding \& Joining 13(2): 97-105. DOI: 10.1179/174329307X249432

10. Oyyaravelu, R., Kuppan, P., and Arivazhagan, N. 2016. Metallurgical and mechanical properties of laser welded high strength low alloy steel. Journal of Advanced Research 7(3): 463-472. DOI: 10.1016/j.jare.2016.03.005

11. Liu, T., Yang, L. J., Wei, H. L., and Qiu, W. C. 2017. Composition change of stainless steels during keyhole mode laser welding. Welding Journal 96(7): 258-s to 270-s.

12. Gu, Z., Yu, S., and Han, L. 2012. Influence of welding speed on microstructures and properties of ultra-high strength steel sheets in laser welding. ISIJ International 52(3): 483-487. DOI: 10.2355/isijinternational.52.483

13. Fahlstrom, K., Persson, K. A., and Larsson, J. K. 2016. Evaluation of laser weldability of 1800 and $1900 \mathrm{MPa}$ boron steels. Journal of Laser Applications 28(2): 022426-1 to 022426-7. DOI: 10.2351/1.4944102

14. Fahlström, K., and Larsson, J. 2013. Laser welding of 1900 MPa boron steel. The $14^{\text {th }}$ Nordic Laser Materials Processing Conference, pp. 16-34. Gothenburg, Sweden. Lulea University of Technology.

15. Kuryntsev, S. V., and Gilmutdinov, A. K. 2015. Heat treatment of welded joints of steel $0.3 \mathrm{C}-1 \mathrm{Cr}-1 \mathrm{Si}$ produced by highpower fiber lasers. Optics \& Laser Technology 74: 125-131. DOI: 10.1016/j.optlastec.2015.06.004

16. Pahole, I., Bonifarti, S., Ficko, M., et al. 2006. Bending of sheet metal of complicated shapes (for 90 angle and more) in combined tools. Journal of Achievements of Materials and Manufacturing Engineering 16(1-2): 88-93.

17. Song, Y., and Hua, L. 2012. Influence of inhomogeneous constitutive properties of weld materials on formability of tailor welded blanks. Materials Science and Engineering A 552: 222-229. DOI: 10.1016/j.msea.2012.05.034

18. Leitao, C., Zhang, B. K., Padmanabhan, R., and Rodrigues, D. M. 2011. Influence of weld geometry and mismatch on formability of aluminium tailor welded blanks: Numerical and experimental analysis. Science and Technology of Welding and Joining 16(8): 662-668. DOI: 10.1179/1362171811Y.0000000055

19. Saha, D. C., Westerbaan, D., and Nayak, S. S. 2014. Microstructure-properties correlation in fiber laser welding of dual-phase and HSLA steels. Materials Science and Engineering A 607: 445-453. DOI: 10.1016/j.msea.2014.04.034

20. Xu, W., Westerbaan, D., Nayak, S. S., et al. 2012. Microstructure and fatigue performance of single and multiple linear fiber laser welded DP980 dual-phase steel. Materials Science and Engineering A 553: 51-58. DOI: 10.1016/j.msea.2012.05.091

21. Mohammadi, A., Vanhove, H., Bael, A. V., and Duflou, J. R. 2012. Bending properties of locally laser heat treated AA2024-T3 aluminium alloy. Physics Procedia 39: 257-264. DOI: 10.1016/j. phpro.2012.10.037

22. Magudeeswaran, G., Balasubramanian, V., and Reddy, G. M. 2008. Effect of welding processes and consumables on tensile and impact properties of high strength quenched and tempered steel joints. Journal of Iron and Steel Research International 15(6): 87-94. DOI: 10.1016/S1006-706X(08)60273-3 
23. Luo, C., Cao, Y., Zhao, Y., and Zhao, L. 2018. Fiber laser welding of 1700-MPa, ultrahigh-strength steel. Welding Journal 97(7): 214-s to 228-s. DOI: 10.29391/2018.97.019

24. Jena, P. K., Mishra, B., Rameshbabu, M., and Babu, D. A. 2010. Effect of heat treatment on mechanical and ballistic properties of a high strength armour steel. International Journal of Impact Engineering 37(3): 242-249. DOI: 10.1016/j.ijimpeng.2009.09.003

25. Li, K., Shan, J., Wang, C., and Tian, Z. 2016. Effect of postweld heat treatments on strength and toughness behavior of T-250 maraging steel welded by laser beam. Materials Science and Engineering A 663: 157-165. DOI: 10.1016/j.msea.2016.03.082

26. Cai, Y., Heng, H., Li, F., and Wang, M. 2018. The influences of welding parameters on the metal vapor plume in fiber laser welding based on 3D reconstruction. Optics \& Laser Technology 107: 1-7. DOI: 10.1016/j.optlastec.2018.05.016

27. Lei, Z., Bi, J., Li, P., et al. 2018. Analysis on welding characteristics of ultrasonic assisted laser welding of AZ31B magnesium alloy. Optics \& Laser Technology 105: 15-22. DOI: 10.1016/ j.optlastec.2018.02.050

28. Romero, P., Rodríguez, F., and Otero, J. 2008. Diode laser correction of spring back effect in forming process of galvanized dual phase steels for automotive application. International Congress on Applications of Lasers \& Electro-Optics, pp. 603-610. Temecula, Calif. Laser Institute of America. DOI: 10.2351/1.5061248

29. Leunda, J., Navas, V. G., Soriano, C., and Sanz, C. 2014. Effect of laser tempering of high alloy powder metallurgical tool steels after laser cladding. Surface and Coatings Technology 259: 570-576. DOI: 10.1016/j.surfcoat.2014.10.028

30. Neugebauer, R., Scheffler, S., Poprawe, R., and Weisheit, A. 2009. Local laser heat treatment of ultra high strength steels to improve formability. Production Engineering 3(4-5): 347. DOI: 10.1007/s11740-009-0186-9

31. Järvenpää, A., Jaskari, M., Hietala, M., and Mäntyjärvi, K. 2015. Local laser heat treatments of steel sheets. Physics Procedia 78: 296-304. DOI: 10.1016/j.phpro.2015.11.040

32. Asadi, M., Frommeyer, G., Aghajani, A., et al. 2011. Local laser heat treatment in dual-phase steels. Metallurgical and Materials Transactions A 43(4): 1244-1258. DOI: 10.1007/s11661-0110943-1

33. Carlsson, B., Russo, D., and Oliver, J. A. 2006. Manufacturing of parts in ultra high strength steel using local heat treatment. The $8^{\text {th }}$ Biennial ASME Conference on Engineering Systems Design and Analysis, pp. 855-858. Torino, Italy. American Society of Mechanical Engineers.

34. Baumann, M., Krause, V., Bergweiler, G., et al. 2012. Local heat treatment of high strength steels with zoom-optics and 10kW-diode laser. High Power Laser Materials Processing: Lasers, Beam Delivery, Diagnostics, and Applications, pp. 82390J-1 to 82390J-9. San Francisco, Calif. International Society for Optics and Photonics. DOI: 10.1117/12.908384

35. Kim, K. B. 2017. Method for laser heat treatment to improve formability of advanced high strength steels. U.S. Patent No. 9670560 B2.

36. Niehuesbernd, J., Monnerjahn, V., Bruder, E., et al. 2016. Improving the formability of linear flow split profiles by laser annealing. Material Science and Materials Technology 47(12): 1174-1181. DOI: 10.1002/mawe.201600577

37. Bammer, F., Holzinger, B., Humenberger, G., et al. 2010. Integration of high power lasers in bending tools. Physics Procedia 5:
205-209. DOI: 10.1016/j.phpro.2010.08.045

38. Zhi-Yong, W., Hong, C., and Tie-Chuan, Z. 2002. Design of strip integral mirror for high power laser processing. Journal of Beijing Polytechnic University 28(3): 334-336. DOI: 10.3969/j.issn.

0254-0037.2002.03.020

39. Tao, X. G., Han, L. Z., and Gu, J. F. 2014. Effect of tempering on microstructure evolution and mechanical properties of $\mathrm{X} 12 \mathrm{Cr}$ MoWVNbN10-1-1 steel. Materials Science and Engineering A 618: 189-204. DOI: 10.1016/j.msea.2014.09.009

40. Liu, F., Lin, X., Song, M., et al. 2016. Effect of tempering temperature on microstructure and mechanical properties of laser solid formed 300M steel. Journal of Alloys and Compounds 689: 225-232. DOI: 10.1016/j.jallcom.2016.07.276

41. Hernandez, V. H., Nayak, S. S., and Zhou, Y. 2011. Tempering of martensite in dual-phase steels and its effects on softening behavior. Metallurgical and Materials Transactions A 42(10): 31153129. DOI: 10.1007/s11661-011-0739-3

42. Xu, L., Chen, L., and Sun, W. 2018. Effects of soaking and tempering temperature on microstructure and mechanical properties of 65Si2MnWE spring steel. Vacuum 154: 322-332. DOI: 10.1016/j.vacuum.2018.05.029

43. Sayed, A. A., and Kheirandish, S. 2012. Affect of the tempering temperature on the microstructure and mechanical properties of dual phase steels. Materials Science and Engineering A 532:

21-25. DOI: 10.1016/j.msea.2011.10.056

44. Lapouge, P., Dirrenberger, J., Coste, F., and Schneider, M. 2019. Laser heat treatment of martensitic steel and dual-phase steel with high martensite content. Materials Science and Engineering A 752: 128-135. DOI: 10.1016/j.msea.2019.03.016

45. Zhang, J., Di, H., Deng, Y., and Misra, R. D. K. 2015. Effect of martensite morphology and volume fraction on strain hardening and fracture behavior of martensite-ferrite dual phase steel. $\mathrm{Ma}$ terials Science and Engineering A 627: 230-240. DOI: 10.1016/j.msea. 2015.01.006

46. Du, C., Hoefnagels, J. P. M., Kölling, S., and Geers, M. G. D. 2018. Martensite crystallography and chemistry in dual phase and fully martensitic steels. Materials Characterization 139: 411-420. DOI: 10.1016/j.matchar.2018.03.011

47. Roumina, R., Bruhis, M., Masse, J. P., et al. 2016. Bending properties of functionally graded $300 \mathrm{M}$ steels. Materials Science and Engineering A 653: 63-70. DOI: 10.1016/j.msea.2015.12.012

48. Uemori, T., Naka, T., Tada, N., et al. 2017. Theoretical predictions of fracture and springback for high tensile strength steel sheets under stretch bending. Procedia Engineering 207: 1594-1598. DOI: 10.1016/j.proeng.2017.10.1054

49. Shi, Z., Liu, K., Wang, M., and Shi, J. 2011. Thermomechanical properties of ultra high strength steel 22SiMn2TiB at elevated temperature. Materials Science and Engineering A 528(10-11): 3681-3688. DOI: 10.1016/j.msea.2011.01.053

CHONG LUO and JGUO SHAN (shanjg@mail.tsinghua.edu.cn) are with the Department of Mechanical Engineering, Tsinghua University, Beijing, China. SHAN is also with the Key Laboratory for Advanced Materials Processing Technology, Ministry of Education, Tsinghua University, Beijing, China. YANG CAO and LIN ZHAO are wth the Central Iron \& Steel Research Institute, Beijing, China. CAO is also with the School of Materials, Tsinghua University, Beijing, China. 